\title{
Phytotelmata colonization in bamboo (Guadua sp.) culms in northeast Argentina
}

\author{
Raúl Ernesto Campos
}

Instituto de Limnología 'Dr. Raúl A. Ringuelet', Universidad Nacional de La Plata - Consejo Nacional de Investigaciones Científicas y Técnicas, CCT La Plata, Buenos Aires, Argentina

\begin{abstract}
This study aimed to determine the susceptibility of stumps and internodes of bamboos to colonization by different types of macroinvertebrates and the formation of communities of different complexity. Semi-controlled field studies were carried out in a subtropical area of Argentina to analyse community structure, species richness of the aquatic macroinvertebrate communities and co-occurrences of predators and prey to delineate the food webs. Water-filled bamboos were sampled every season during a year by removing, without replacing, all water and macroinvertebrates. This study shows that the variation in the morphology of the container provides different resources, leading to segregation of species per container type, and allowing each of them to establish aquatic communities with differences in diversity. The Diptera was best represented in the communities of bamboos, where Culicidae showed the highest species richness and Ceratopogonidae were the most abundant numerically. Eleven taxa were present in both phytotelmata, 12 were unique in internodes and 13 in stumps. The community in internodes was composed of 21 taxa where mosquitoes were represented by Sabethini and Toxorhynchitini. By contrast, stumps were colonized by 24 taxa and Ceratopogonidae were numerically dominant. Regarding food webs established in stumps and internodes, no differences in length were found, except for the species that played equivalent roles in each of the studied phytotelmata.
\end{abstract}

\section{ARTICLE HISTORY}

Received 27 March 2014

Accepted 2 September 2015

Online 7 October 2015

\section{KEYWORDS}

Phytotelmata; biodiversity; food web; Culicidae;

Ceratopogonidae; Neotropical region

\section{Introduction}

The phytotelmata are aquatic microhabitats with well-defined characteristics. They are formed by the accumulation of fallen water or exudates in cavities of plants (leaf, flowers, stems, fruits, or bracts), being mostly temporary and of small size (Fish 1983). Some phytotelmata formed in culms of bamboo can hold water for a long time and therefore allow the settling of macroinvertebrate communities. Bamboos form two types of microhabitats: the culm segments (internodes), which are practically closed except for the punctures in the wall made by boring insects (Macdonald 1962; Kovac and Azarae 1994), and the stumps that are formed by a rupture or transverse cut of the stem. They 
can be open or semi-closed when the nodal diaphragm covers $50 \%$ or more of the bottom area above the water surface (Sunahara and Mogi 1997).

Species of woody bamboo with a hollow culm able to retain water are distributed in all continents except Europe and Antarctica. However, most of the studies on their phytotelmata arise from tropical and subtropical Asia (e.g. Japan: Mogi and Suzuki 1983; Malaysia: Kovac and Streit 1996; India: Aditya et al. 2008), and refer to the macroinvertebrate communities that inhabit them, with emphasis on culicids.

In the Americas, a total of 420 species of woody bamboo are known, representing $44 \%$ of the world's woody bamboo species (Londoño 1996). However, little is known of their aquatic communities. Davis (1944) carried out the first study in this region on the habitats of mosquitoes, providing a list of species found in bamboo from Brazil and describing those that use other phytotelmata as breeding sites. The first integral study of the invertebrate community was carried out by Louton et al. (1996) in Peru. These authors studied the structure of the community and the trophic chain from aquatic ecosystems in internodes of Guadua weberbaueri Pilger. Lozovei (1998-2001) in Brazil studied the mosquito communities that inhabit Merostachys spp. phytotelmata. This author recorded 17 species of mosquitoes, most of them of the Sabethini tribe, and highlighted the specialization of the females to localize the breeding sites. Martins Da Silva et al. (2004) reported three culicids, two native species and the invasive Aedes (Stegomyia) albopictus (Skuse), from stumps of bamboo in the Brazilian Atlantic Forest, and Zequi and Lopes (2001), reported 10 mosquito species inhabiting Merostachys bamboo, in a bush in the urban area of Londrina, Brazil, where Sabethini were dominant. In Colombia, Barajas et al. (2013) reported nine mosquito species breeding in internodes and stumps of Guadua angustifolia Kunth. These authors found a relationship between the species of mosquitoes and water volume and height above ground.

Ecological aspects of bamboo's microhabitats from Argentina were less explored. In a study on coleopterans associated with phytotelmata from Argentina (Campos and Fernández 2011) a list of families of aquatic, semi-aquatic and terrestrial coleopterans found in the internodes of bamboo is given. Another study records the species of Culicidae and Ceratopogonidae that inhabit bamboo internodes in the subtropical forest of northeastern Argentina (Campos et al. 2011). A study considering ecological aspects refers to the macroinvertebrate communities that inhabit two sympatric bamboos of the genus Guadua Kunth (Campos 2013); it described the structure of the communities, species abundance in relation to environmental variables, and assembly of species that inhabit internodes, concluding that the macroinvertebrate communities differ from both Guadua species, but many of the inhabitants use indistinctly both phytotelmata as breeding sites.

Little is known of the species diversity of the macroinvertebrate communities that develop in different species of bamboo and of their degree of specificity. The best studied taxon, because of its medical importance, is Culicidae; but we are far from having a complete record of species that use this type of microhabitat as a breeding site. In the Neotropical region, approximately 72 species of culicid found in bamboo have been reported, of which 54 have been identified and 18 remain unidentified (Davis 1944; Louton et al. 1996; Lozovei 1998, 2001; Campos et al. 2011; Campos 2013). 
Few studies have compared communities of invertebrates within different species of bamboos, or under different conditions. Sunahara and Mogi (1997) studied the distribution of mosquito larvae between two types of stumps, open and semi-open, and found that the density of Aedes albopictus was positively correlated with the number of leaves trapped in the stump, whereas the density of Tripteroides bambusa (Yamada) was not. Moreover, it was observed that temporal variations in persistence of habitat and input of resource into the stumps of bamboo could facilitate the coexistence of the two species of mosquitoes. Sunahara et al. (1999) compared the mosquito communities that inhabit drought-prone stumps versus drought-resistant ones and concluded that the use of the stumps by Aedes (Stegomyia) spp. and Tripteroides spp. was differentially limited by their susceptibility to droughts, stump morphology and possible interactions with predators and large detritivores.

Several studies were devoted to the seasonality of insect populations and communities inhabiting phytotelmata in South America (e.g. Lounibos et al. 1987; Campos and Lounibos 1999; Marti et al. 2007; Montero et al. 2010); however, the communities living in bamboo internodes have not been studied in this aspect.

Although a wide diversity of macroinvertebrates has been reported from Guadua bamboo in South America, their habitat segregation has not been investigated in detail. The main purpose of the present study is to describe the communities that inhabit stumps and internodes from the same species of bamboo. Taking into account that the same species of bamboo may provide two morphological types of aquatic microhabitats, and presumably is able to accommodate different quality and quantity of detritus, it was speculated that the species richness and assembly, and community structure of macroinvertebrates could be different, segregation being possible by a determined type of microhabitat. To substantiate this hypothesis, the following objectives were formulated: (1) comparison of the structure, species richness and seasonality of the aquatic macroinvertebrate communities in two phytotelmata formed in bamboo culms, (2) comparison of the co-occurrence of the top predator with the most abundant aquatic macroinvertebrates in both bamboo phytotelmata, and (3) exhibition of a hypothetical food web from communities in stumps and internodes.

\section{Material and methods}

\section{Study area}

The field study was conducted from September 2011 to October 2012 in the Biological Station of Corrientes (EBCO Spanish abbreviation) (27 $\left.32^{\prime} 43^{\prime \prime} \mathrm{S}, 58^{\circ} 40^{\prime} 23^{\prime \prime} \mathrm{W}\right)$, located in San Cayetano, Riachuelo, northwest of Corrientes Province, Argentina. The site where the study was carried out is a native cane field located on the margin of Riachuelo River. The Biological Station is situated on the east of the biogeographic Chaqueña Province, characterized by subtropical climate, xerophylic and perishable wood and savanna, forming on the east a transition area with the sylvan Paranense Province. Annual mean temperature and precipitation are $23^{\circ} \mathrm{C}$ and $1200 \mathrm{~mm}$, with rains falling predominantly in summer (Cabrera and Willink 1980). 


\section{Sampling}

The experiment was designed in order for the process of succession to start at the same time in all stumps and internodes. Sixty bamboos of Guadua sp. were selected for the experiment. Thirty were used as stumps and thirty as internodes. Bamboos for stumps were cut between 1 and $1.50 \mathrm{~m}$ from ground level (Figure 1A). Bamboos for internodes were drilled at the same height as the stumps. One $5-\mathrm{mm}$ diameter hole was made in the middle of the internode wall to facilitate colonization by insects. The size was chosen because according to a previous study this is the most frequent size of the holes in nature (Campos 2013). The holes were oriented in different directions but this was not considered as a variable in the present study. A second $2.5-\mathrm{cm}$ diameter hole was made, up to the level of the first hole to extract the samples (Figure 1B). This hole stayed hidden with a cork, except when the sample was extracted. To prevent the cork from monkey predation, it was strapped as shown in Figure 1C. The spatial arrangement of the stumps and internodes was in pairs (one stump and one internode) randomly distributed. All stumps and internodes were in the shade because of the density of the cane, which prevents the direct passage of sunlight. Previous to the initiation of the experiment, exudates were extracted from both, stumps and internodes. From the start to the end of each season, stumps and internodes were filled naturally with rainwater and exudates of the bamboo. At the end of the season, all contents (fluid, debris and insects) were extracted, and the natural cycle was initiated again in the next season. Standing water containing insects was extracted with a pooter (aspirator) attached to a lift pump (Figure 1D), and the volume of water was measured. Internodes and stumps were washed and re-extracted several successive times with clean tap water until no insects or sediments were observed in the extracted water. Samples were taken at the end of every season during a year. All macroinvertebrates (aquatic and semi-aquatic) were killed in the field and preserved in $80 \%$ commercial ethyl alcohol, except for some immature forms, which were carried alive to the laboratory in individual plastic tubes to be reared and identified.

Taxonomic resolution was attempted to species level and for this reason some late instar larvae and pupae of insects recognized as different morphospecies were reared to adulthood. Other taxa different from Ceratopogonidae and Culicidae were identified to order or family using the keys of Stehr (1987-1991). Ceratopogonidae were identified by specialists and the Culicidae were identified by the author of the present study.

The inner diameter ( $i$ ) and depth measured from bottom (basal node) to level of the hole $(d)$ of each culm were measured. Capacity $(c)$ of each internode and stump was determined as $\pi i^{2} d / 4$ (Sota and Mogi 1996). The $\mathrm{pH}$ was measured with $\mathrm{pH}$ indicator strips $\left(\right.$ Merck $\left.{ }^{\circledR}\right)$ after extraction.

\section{Data analyses}

Statistical analyses were performed for whole aquatic and semi-aquatic macroinvertebrate communities. Mann-Whitney $U$-tests and Student's $t$-tests were used to estimate significant variations in abiotic parameters (physical, chemical and morphological) among phytotelmata types. 

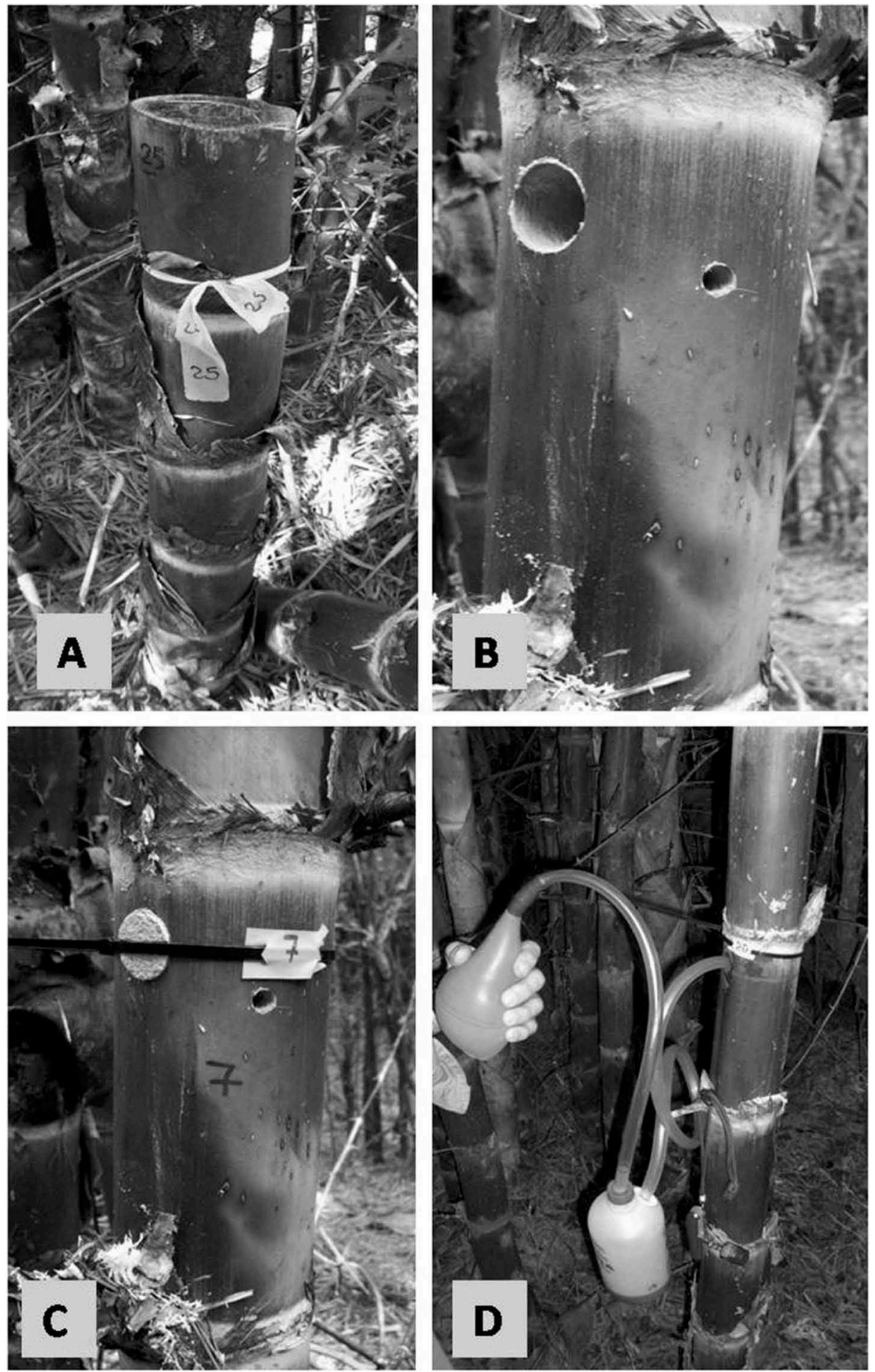

Figure 1. Stumps and internodes of Guadua sp. (Poaceae) used to study the macroinvertebrate communities in Corrientes Province, Argentina. (A) Stump. (B) Internode showing the holes performed for sample extraction (bigger) and inlet for macroinvertebrates. (C) Internode showing the final aspect. (D) Pooter (aspirator) attached to a lift pump used to extract the samples from internodes of bamboo. 
Diversity, evenness and dominance of macroinvertebrates from internode and stump were measured by Shannon-Wiener $(H)$, Pielou $(E)$ and Berger-Parker $(d)$ indexes, respectively (Magurran 1988), which were calculated for each unity of sample. As the data obtained from samples violated the assumption of normality and homogeneity of variances, the non-parametric two-way analysis of variance with Scheirer-Ray-Hare extension of the Kruskal-Wallis test (Scheirer et al. 1976; as described in Sokal and Rohlf 1995) was used to determine the main and interactive effects of each variable (microhabitat and season) on the indexes, number of individuals and taxa. Subsequently, the variables that showed significant differences were tested with the Kruskal-Wallis test. Multiple comparisons were performed by Mann-Whitney U-tests. To compromise between a large overall Type I error, which would arise with an a of 0.05 for each separate test, and a large overall Type II error, which would arise with a strict application of Bonferroni correction, an a of 0.008 in each separate post hoc test was used (Nugues and Bak 2006).

Similarity between the four seasons related to macroinvertebrate communities was analysed by cluster analysis, using arithmetic averages (UPGMA) and the unweighted pairgroup method. For cluster analysis, the Morisita-Horn index was used because it is not dependent on sample size, and is the index least influenced by species richness (Wolda 1981).

Interspecific associations were studied using the $C_{8}$ coefficient (Hurlbert 1969), for the top predator versus mosquitoes and other abundant taxa, by each phytotelmata type and seasons. Significance association was tested by $x^{2}$ corrected for continuity.

\section{Results}

\section{Habitat characteristics}

Thirty internodes and 30 stumps of bamboo of the genus Guadua were measured (Table 1). The depth of culm, and the internal diameter and capacity of both microhabitats were not significantly different $\left(t_{\text {Depth }}=-0.8 ; \mathrm{df}=58 ; p=0.43 ; t_{\text {Diameter }}=1 ; \mathrm{df}=28\right.$; $p=0.32 ; U_{\text {Capacity }}=955 ; n=30 ; p=0.56$ ). The $\mathrm{pH}$ in stumps was a little alkaline in winter and summer and neutral in autumn and spring, while $\mathrm{pH}$ in internodes was acid in winter, a little alkaline in spring and neutral in summer and autumn. The $\mathrm{pH}$ between stumps and internodes was significantly different in spring, winter and autumn $\left(U_{\text {Spring }}=1126 ; n=29\right.$ 30; $p<0.001 ; U_{\text {Winter }}=537 ; n=17-27 ; p<0.001 ; U_{\text {Autumn }}=663 ; n=28-29 ; p<0.01$ ), except summer $\left(U_{\text {summer }}=655 ; n=27-28 ; p=0.09\right)$. The water volume was significantly greater in internodes than in stumps in all seasons $\left(t_{\text {spring }}=3.75 ; \mathrm{df}=56 ; t_{\text {summer }}=4.41\right.$; $\left.\mathrm{df}=53 ; U_{\text {Autumn }}=1036 ; n=28-29 ; U_{\text {Winter }}=208 ; n=17-27 ; p<0.001\right)$. Percentages of internodes and stumps retaining water in each season were: internodes, $100 \%$ in spring, $99.1 \%$ in summer, $99.4 \%$ in autumn and $99.1 \%$ in winter, and stumps, $100 \%$ in spring; $99.4 \%$ in summer; $99.7 \%$ in autumn and $96.4 \%$ in winter.

\section{Taxonomic considerations}

Because the taxonomy of the immature stages of the genus Wyeomyia Theobald is confusing, larvae collected could not be differentiated by species. However, from the larvae reared to obtain adults (males and females), Wyeomyia codiocampa Dyar and 
Table 1. Morphometric data and water parameters from 30 internodes and 30 stumps of Guadua phytotelmata, from Corrientes Province, Argentina.

\begin{tabular}{|c|c|c|c|c|}
\hline Parameter & Season & Internodes & & Stumps \\
\hline Culm depth $(\mathrm{cm})$ & & $13.67 \pm 2.82$ & & $14.18 \pm 2.02$ \\
\hline Internal diameter $(\mathrm{cm})$ & & $3.53 \pm 0.76$ & & $3.36 \pm 0.59$ \\
\hline Capacity (ml) & & $125.31(85.82-182.12)$ & & $110.81(95.81-162.27)$ \\
\hline \multirow[t]{4}{*}{$\mathrm{pH}$} & Spring & $8(8-8)$ & $* *$ & $7(6-8)$ \\
\hline & Summer & $7(7-8)$ & & $8(7-8)$ \\
\hline & Autumn & $7(7-7)$ & $*$ & $7(7-8)$ \\
\hline & Winter & $6(6-7)$ & ** & $8(7-8)$ \\
\hline \multirow[t]{4}{*}{ Water volume } & Spring & $118.1 \pm 53.12$ & ** & $73.7 \pm 35.30$ \\
\hline & Summer & $105.3 \pm 48.42$ & ** & $58.1 \pm 28.81$ \\
\hline & Autumn & $102.50(76.50-125.50)$ & ** & $56(33.25-88.75)$ \\
\hline & Winter & $87(55.50-108.75)$ & ** & 31 (13.75-44.75) \\
\hline
\end{tabular}

Data analysed by $t$-test and Mann-Whitney $U$-test, are shown as mean \pm standard deviation, and median and interquartile (Q1-Q3), respectively. Significant differences are denoted by asterisk across rows ${ }^{*} p<0.01,{ }^{* *} p<0.001$.

Knab and another unidentified Wyeomyia could be identified. Therefore, for statistical analyses, and ecological indices both species are treated together as Wyeomyia spp. All adults of the genus Toxorhynchites Theobald, obtained from rearing larvae and pupae from bamboo internodes corresponded to Toxorhynchites guadeloupensis (Dyar and Knab) using Darsie (1985) and Lane (1953) as keys for females and males, respectively. Therefore, all larvae collected from bamboo internodes were attributed to this species. In contrast, adults could not be obtained from larvae of stumps; so they are cited as Toxorhynchites sp. The Culicoides Latreille larvae collected could not be differentiated by species. However, from the larvae reared to obtain adults, Culicoides bambusicola (Lutz), Culicoides austroparaensis Spinelli and Culicoides sp. nov. were identified. Therefore, for statistical analyses and ecological indices, these species are treated together as Culicoides spp.

\section{Composition of macroinvertebrate communities}

The number of individuals of macroinvertebrates collected from stumps ( $n=4741$ ) was twice that collected from internodes $(n=2452)$. The total number of aquatic and semi-aquatic taxa identified was higher in stumps $(n=24)$ than in internodes $(n=21)$ (Table 2), whereas the number of co-inhabiting taxa was higher in internodes $(n=7)$ than in stumps $(n=5)$. The taxa were represented mainly by immature insects. Order Diptera was best represented in the communities of bamboos, with family Culicidae as more species dominance and Ceratopogonidae as more abundant. The richness of species and morphospecies of mosquitoes was higher in stumps $(n=4)$ than in internodes $(n=3)$; however, the abundance of individuals was 11 times higher in internodes than in stumps. Eleven taxa were present in both phytotelmata, 12 were unique in internodes and 13 in stumps. In both microhabitats, exclusive groups belonged predominantly to the order Diptera (Table 2). Only one species was a singleton in stumps (Liodessus sp.), and three taxa were singletons in internodes (Nematoda, Cecidomyiidae sp. 1 and Fannidae). Five obligate and three facultative predators were identified, T. guadeloupensis, Toxorhynchites sp., Corethrella sp., Systenus sp. Liodessus sp., and Culicoides spp., Sabethes aurescens (Lutz) and 
Table 2. Taxonomic classification of the macroinvertebrates inhabiting internodes and stumps of Guadua sp. phytotelmata, from Corrientes Province, Argentina.

\begin{tabular}{|c|c|c|c|c|c|c|c|c|}
\hline \multirow[b]{2}{*}{ Taxa } & \multicolumn{4}{|c|}{ Internodes } & \multicolumn{4}{|c|}{ Stumps } \\
\hline & $S$ & $\mathrm{Su}$ & A & W & $S$ & Su & A & W \\
\hline \multicolumn{9}{|l|}{ Annelida } \\
\hline Oligochaeta & & 1 & & 4 & 11 & 129 & 22 & 57 \\
\hline Nematoda & 1 & & & & 2 & & & \\
\hline Acari & & & & & 5 & 3 & 1 & \\
\hline \multicolumn{9}{|l|}{ Hexapoda } \\
\hline Collembola & & & & & 1 & 1 & & \\
\hline Coleoptera & & & & & & & & \\
\hline Dytiscidae: Liodessus sp. & & & & & 1 & & & \\
\hline Nitidulidae & 34 & & & & & & & \\
\hline \multicolumn{9}{|l|}{ Diptera } \\
\hline Tipulidae & 7 & & & & 9 & & & \\
\hline \multicolumn{9}{|l|}{ Cecidomyiidae } \\
\hline Sp. 1 & & 1 & & & 10 & 5 & & 1 \\
\hline Sp. 2 & & & & & 7 & & & \\
\hline Psychodidae & 4 & & & 10 & 40 & 1 & 51 & 3 \\
\hline Scatopsidae & 41 & 7 & & & & & & \\
\hline Corethrellidae: Corethrella sp. & 3 & 53 & 23 & 26 & 2 & 4 & & 4 \\
\hline \multicolumn{9}{|l|}{ Culicidae } \\
\hline Toxorhynchites guadeloupensis (Dyar \& Knab) & 7 & 3 & 4 & 11 & & & & \\
\hline Toxorhynchites sp. & & & & & 7 & & & 4 \\
\hline Wyeomyia spp. & 71 & 16 & 90 & 40 & 1 & & 1 & \\
\hline Sabethes aurescens (Lutz) & 19 & & 1 & & & & & \\
\hline Sabethes undosus (Coquillett) & & & & & & & & 2 \\
\hline Aedes terrens (Walker) & & & & & 6 & 3 & & \\
\hline \multicolumn{9}{|l|}{ Ceratopogonidae } \\
\hline Culicoides spp.* & 15 & 287 & 77 & 142 & 893 & 2180 & 787 & 260 \\
\hline Forcipomyia sp. & 23 & 2 & 1 & 2 & 1 & & 1 & 2 \\
\hline Dolichopodidae: Systenus sp. & 2 & 1 & 1 & & & & & \\
\hline Phoridae & 8 & 1 & & & & & & \\
\hline Syrphidae Sp. 1 & 28 & 5 & 2 & 4 & 2 & & & \\
\hline Syrphidae Sp. 2 & & & & & 103 & 4 & & 10 \\
\hline Drosophilidae & 10 & 2 & & & 2 & & & \\
\hline Fannidae & 1 & & & & & & & \\
\hline Unidentified Nematocera & & & & & 4 & & & \\
\hline Unidentified Brachycera Sp. 1 & 1361 & & & & 3 & 21 & 61 & 9 \\
\hline Unidentified Brachycera Sp. 2 & & & & & 4 & & & \\
\hline Total & 1635 & 379 & 199 & 239 & 1114 & 2351 & 924 & 352 \\
\hline
\end{tabular}

S, Spring; Su, Summer; A, Autumn; W, Winter.

*Includes Culicoides bambusicola (Lutz), Culicoides austroparaensis Spinelli and Culicoides sp. nov.

Sabethes undosus (Coquillet) respectively. The Toxorhynchites spp. and Corethrella sp. obligate predators were present in both microhabitats, and Systenus sp. and Liodessus sp. were only present in the internodes and stumps, respectively. The two species of Toxorhynchites were larger predators in both microhabitats. The facultative predators Culicoides spp. were present in both microhabitats, and S. aurescens and S. undosus were found only in internodes and stumps, respectively. Brachycera morphotype 1 was the dominant species in internodes and Culicoides spp. in stumps (Table 2).

\section{Seasonality of macroinvertebrates in internodes and stumps}

The number of individuals per microhabitat for each season was predominantly higher in stumps than in internodes, except during the spring when the average for internodes was 
higher than in stumps (Table 3). Considering that the effect of different microhabitats on the mean number of individuals depends on the season, a statistically significant interaction between both variables was observed $(p<0.001)$ (Table 4). Internodes contain greater amounts of macroinvertebrates in the spring, whereas the stumps contain more in summer. In internodes and stumps the lower abundance of individuals occurred in autumn and winter, respectively (Table 3). The number of taxa in internodes (mean \pm SD; $2.5 \pm 0.98$ ) was significantly higher than in stumps $(1.9 \pm 0.69)$, and both presented a significant seasonal variation, but no interactions were detected between variables (Table 5). In both internodes and stumps, the number of taxa was higher and significant in spring in comparison to the other seasons (Tables 3 and 5). The Shannon-Wiener index of diversity differs significantly between microhabitats $\left(\mathrm{H}_{\text {Internode }}^{\prime}=0.53, \mathrm{H}_{\text {Stump }}^{\prime}=0.33\right)$ and between seasons, but no significant interactions were detected between variables (Table 6). Seasonal variation shows that in the internodes the macroinvertebrates diversity is greater and significant in spring compared with the autumn and winter, but not significantly different from summer. Whereas in stumps, significant differences occurred in spring, with respect to summer, autumn and winter (Tables 3 and 6). No significant differences were detected for evenness either in microhabitat $(\mathrm{F}=0.31, \mathrm{df}=1, p=0.58$ ) or seasons $(\mathrm{F}=1.30, \mathrm{df}=3, p=0.27$ ) (Table 3).

The Berger-Parker index of dominance $(d)$ also showed significant differences between the two variables, but not among their interactions (Table 7). Seasonal variation shows that in the internodes the dominance of macroinvertebrates is greater and significant in winter compared with spring, but was not significantly different between the others seasons. Whereas in stumps, significant differences occurred in spring, when a lower index was observed, with respect to summer and autumn (Tables 3 and 7).

Morisita-Horn indexes for internodes (Figure 2A) showed a cluster comprising spring, summer and winter communities, separated from autumn. Whereas for stumps (Figure $2 \mathrm{~B}$ ), the main cluster was strongly separated from the winter community.

\section{Species association}

The association of the main predator, Toxorhynchites spp. with the most abundant species in the internodes and stumps, was studied in all seasons. Of all the species pairs analysed in internodes, $T$. guadeloupensis was strongly associated with Wyeomyia spp. in summer $\left(C_{8}=1, X^{2}\left(\mathrm{df}_{1)}=6.67, p<0.01\right)\right.$. In stumps, Culicoides spp. showed a strong and highly significant negative association with Toxorhynchites, in winter $\left(C_{8}=-1, X^{2}\right.$ (df 1) $\left.=11.8, p<0.001\right)$. In spring, only Aedes terrens (Walke) showed a slight but significant association with the predator $\left(C_{8}=0.26, X_{(d f 1)}^{2}=8.23, p<0.01\right)$.

\section{Discussion}

\section{Community differences between phytotelmata}

The difference in metazoan fauna that inhabits the internodes and stumps cannot be attributed to the water-holding capacity of these microhabitats because no significant differences were observed between them, but it can be attributed to the size and 


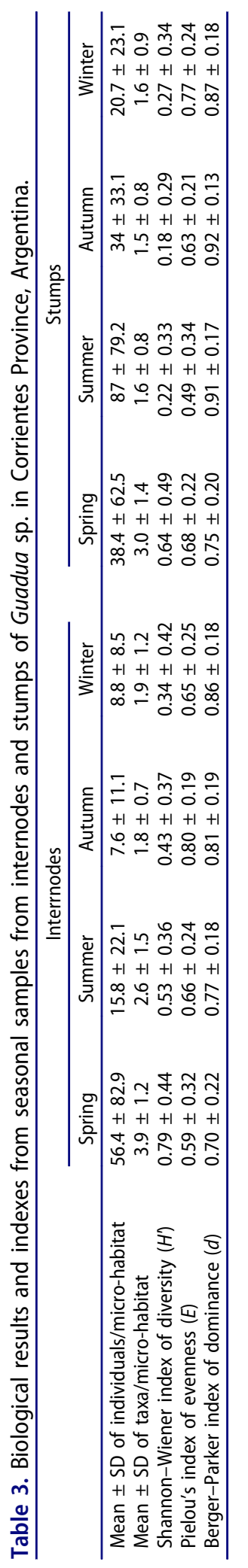


Table 4. Results of two-way analysis of variance with Scheirer-Ray-Hare extension on the ranks of mean number of individuals by microhabitats and seasons, and Kruskal-Wallis test within seasons.

\begin{tabular}{|c|c|c|c|c|}
\hline Source of variation & df & SS & $\mathrm{SS} / \mathrm{MS}_{\text {Total }}$ & $p$-value \\
\hline Microhabitat & 1 & 103554.15 & 29.18 & $<0.001$ \\
\hline Season & 3 & 70609.31 & 19.89 & $<0.001$ \\
\hline \multirow[t]{2}{*}{$M \times S$} & 3 & 66731.65 & 18.80 & $<0.001$ \\
\hline & & $\mathrm{H}$ & & \\
\hline Internodes & 3 & 24.54 & & $<0.001$ \\
\hline \multirow[t]{2}{*}{ Stumps } & 3 & 20.93 & & $<0.001$ \\
\hline & \multicolumn{2}{|c|}{ Internodes } & \multicolumn{2}{|c|}{ Stumps } \\
\hline Comparisons & $U$ & & $U$ & \\
\hline Spring - Summer & 513 & ns & 984 & * \\
\hline Spring - Autumn & 458 & * & 826 & ns \\
\hline Spring - Winter & 539 & * & 346 & ns \\
\hline Summer - Autumn & 718 & ns & 916 & $*$ \\
\hline Summer - Winter & 690 & ns & 225 & * \\
\hline Autumn - Winter & 658 & ns & 304 & ns \\
\hline
\end{tabular}

Post hoc multiple comparisons by Mann-Whitney $U$-test. Level of significance (Bonferroni correction applied) ${ }^{*} p<0.05$, $\mathrm{ns}=$ not significant.

Table 5. Results of two-way analysis of variance with Scheirer-Ray-Hare extension on the ranks of number of taxa by microhabitats and seasons, and Kruskal-Wallis test within seasons.

\begin{tabular}{|c|c|c|c|c|}
\hline Source of variation & df & SS & $\mathrm{SS} / \mathrm{MS}_{\text {Total }}$ & $p$-value \\
\hline Microhabitat & 1 & 35894.38 & 10.89 & $<0.001$ \\
\hline Season & 3 & 71015.08 & 21.54 & $<0.001$ \\
\hline \multirow[t]{2}{*}{$M \times S$} & 3 & 10059.84 & 3.05 & $>0.1$ \\
\hline & & $\mathrm{H}$ & & \\
\hline Internodes & 3 & 40.20 & & $<0.001$ \\
\hline \multirow[t]{2}{*}{ Stumps } & 3 & 22.55 & & $<0.001$ \\
\hline & \multicolumn{2}{|c|}{ Internodes } & \multicolumn{2}{|c|}{ Stumps } \\
\hline Comparisons & $U$ & & $U$ & \\
\hline Spring - Summer & 460 & $*$ & 559 & * \\
\hline Spring - Autumn & 402 & * & 535 & $*$ \\
\hline Spring - Winter & 461 & * & 268 & * \\
\hline Summer - Autumn & 701 & ns & 782 & ns \\
\hline Summer - Winter & 720 & ns & 379 & ns \\
\hline Autumn - Winter & 718 & ns & 403 & ns \\
\hline
\end{tabular}

Post hoc multiple comparisons by Mann-Whitney U-test. Level of significance (Bonferroni correction applied) ${ }^{*} p<0.05$, ns $=$ not significant.

position of the access holes. The amount and size of organic matter entering the internode is limited by the small size and location of the hole. This also produces phytotelmata that are contained within an almost closed cylinder, avoiding loss of water by evaporation and allowing a more stable microenvironment. In contrast, the large opening and horizontal position of the stumps favours the entry of detritus, as well as the entry of rainwater and evaporation, which allows a larger amplitude fluctuation in the water level. These morphological differences have implications on the fauna that will colonize each microhabitat. Aedes terrens females, a species whose eggs require a dry period before hatching, selected the stumps as an oviposition site, where the water level fluctuation would promote hatching. Also the Psychodidae larvae that live preferably associated with decaying organic matter (Stehr 1991), colonized mostly stumps, possibly 
Table 6. Results of two-way analysis of variance with Scheirer-Ray-Hare extension on the ranks of diversity Shannon-Weiner index $\left(\mathrm{H}^{\prime}\right)$ by microhabitats and seasons, and Kruskal-Wallis test within seasons.

\begin{tabular}{|c|c|c|c|c|}
\hline Source of Variation & $\mathrm{df}$ & SS & $\mathrm{SS} / \mathrm{MS}_{\text {Total }}$ & $p$-value \\
\hline Microhabitat & 1 & 36070.49 & 10.89 & $<0.001$ \\
\hline Season & 3 & 104613.85 & 31.59 & $<0.001$ \\
\hline \multirow[t]{2}{*}{$M \times S$} & 3 & 9235.06 & 2.79 & $>0.1$ \\
\hline & & H & & \\
\hline Internodes & 3 & 14.98 & & $<0.001$ \\
\hline \multirow[t]{2}{*}{ Stumps } & 3 & 19.56 & & $<0.001$ \\
\hline & \multicolumn{2}{|c|}{ Internodes } & \multicolumn{2}{|c|}{ Stumps } \\
\hline Comparisons & $U$ & & $U$ & \\
\hline Spring - Summer & 448.5 & ns & 565.5 & * \\
\hline Spring - Autumn & 563 & $*$ & 540 & * \\
\hline Spring - Winter & 517 & * & 271 & * \\
\hline Summer - Autumn & 541.5 & ns & 774 & ns \\
\hline Summer - Winter & 587 & ns & 388 & ns \\
\hline Autumn - Winter & 740 & ns & 413 & ns \\
\hline
\end{tabular}

Post-hoc multiple comparisons by Mann-Whitney $U$-test. Level of significance (Bonferroni correction applied) ${ }^{*} p<0.05$, $\mathrm{ns}=$ not significant.

Table 7. Results of two-way analysis of variance with Scheirer-Ray-Hare extension on the ranks of Berker-Parquer index of dominance $(d)$ by microhabitats and seasons, and Kruskal-Wallis test within seasons.

\begin{tabular}{|c|c|c|c|c|}
\hline Source of variation & $\mathrm{df}$ & SS & $\mathrm{SS} / \mathrm{MS}_{\text {Total }}$ & $p$-value \\
\hline Microhabitat & 1 & 35894.38 & 10.89 & $<0.001$ \\
\hline Season & 3 & 71015.08 & 21.54 & $<0.001$ \\
\hline \multirow[t]{2}{*}{$M \times S$} & 3 & 10059.84 & 3.05 & $>0.1$ \\
\hline & & $\mathrm{H}$ & & \\
\hline Internodes & 3 & 11.29 & & $<0.01$ \\
\hline \multirow[t]{2}{*}{ Stumps } & 3 & 13.72 & & $<0.01$ \\
\hline & \multicolumn{2}{|c|}{ Internodes } & \multicolumn{2}{|c|}{ Stumps } \\
\hline Comparisons & $U$ & \multicolumn{3}{|c|}{$U$} \\
\hline Spring - Summer & 715 & ns & 917 & * \\
\hline Spring - Autumn & 860 & ns & 947 & * \\
\hline Spring - Winter & 921 & $*$ & 470 & ns \\
\hline Summer - Autumn & 570 & ns & 714 & ns \\
\hline Summer - Winter & 522 & ns & 370 & ns \\
\hline Autumn - Winter & 645 & ns & 349 & ns \\
\hline
\end{tabular}

Post-hoc multiple comparisons by Mann - Whitney U-test. Level of significance (Bonferroni correction applied) ${ }^{*}=p<0.05, \mathrm{~ns}=$ not significant.

because of the accumulation of greater amounts of detritus. Conversely, Wyeomyia codiocampa, used almost exclusively internodes. During the present study, the females were observed flying in slow motion, up and down around bamboo stalks to locate the entry holes. Although as mentioned above, some species select one of these microhabitats, others use the stumps and internodes interchangeably, but with large differences in their respective abundances. For example, Corethella sp. was much more abundant in the internodes than in stumps, whereas the reverse situation was observed with the Oligochaeta. Culicoides spp., whose relative abundance was high in both microhabitats, marked a strong preference for stumps where the 

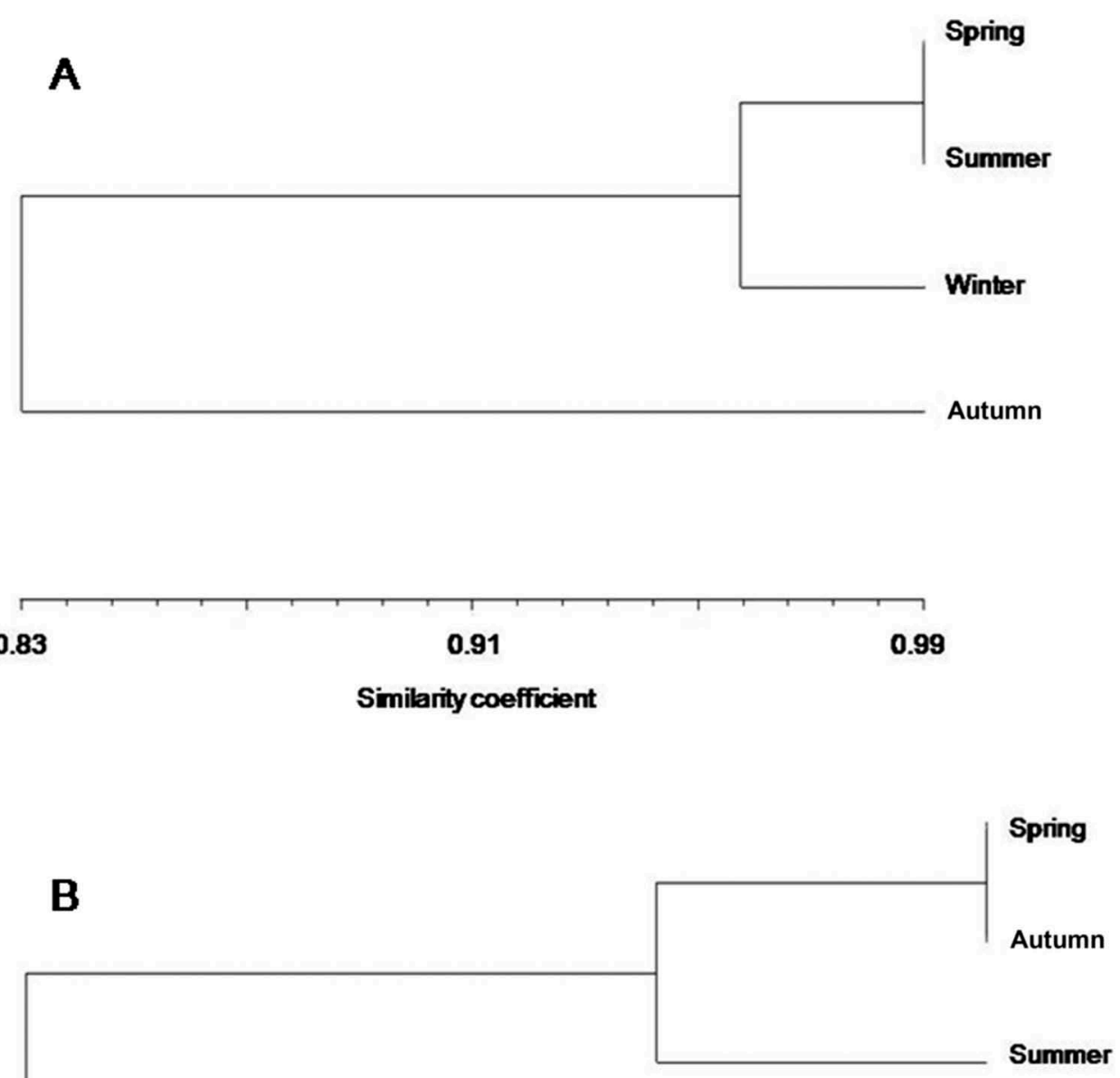

0.98

0.99

1.00

\section{Similarity coefficient}

Figure 2. Cluster analysis of the communities inhabiting. A: internodes and B: stumps using Morisita-Horn index and UPGMA linkage.

number of individuals was eight times higher than in the internodes. Taxa such as Nitidulidae, Scatopsidae, Dolichopodidae, Phoridae and Fannidae were unique components of the community of the internodes, and their presence was limited and restricted only to certain seasons.

From the results obtained in this study, it is inferred that the stumps contain a mixed macroinvertebrate community, consisting of species of both internodes and tree holes. 
However, the small size and capacity of the stumps compared with the large tree holes, seems to limit both the number of macroinvertebrates and the diversity of taxa. For example, in tree holes of the region, Mecistogaster amalia (Burmeister, 1839) nymphs (Odonata: Pseudostigmatidae) (Muzón et al. 2010) were found, being the top predators of these communities, although no nymphs were found in bamboo stumps during this study. In contrast, Aedes terrens, a mosquito that is a frequent and abundant inhabitant of treeholes (pers. obs.), was also found in the stumps, although its abundance and frequency were low and markedly seasonal. Meanwhile, Corethrella sp., a common inhabitant of the tree holes, was observed in both stumps and internodes, although mainly in the latter. Although I could not identify to species level, I speculate that the species found in the stumps could be the same that lives in tree holes because many species use either of these two types of phytotelmata as a breeding site (Borkent 2008).

\section{Seasonality}

During the present study no seasonal differences in the availability of microhabitats were observed. Over $96 \%$ of the stumps and internodes studied contained sufficient water during all seasons, facilitating colonization by macroinvertebrates. However, it was observed that communities differ in their parameters. The abundance of macroinvertebrates was influenced by the type of microhabitat per season. The stumps harboured more individuals than internodes, but fewer species, both increasing during the warm seasons. The communities of stumps were dominated in all seasons by Culicoides larvae, which began to pupate in spring. However, this pattern was not observed in the internodes. The cause of the greater diversity of macroinvertebrates in relation to the stumps or internodes remains in question. However, one reason could be that those species that require dark environments as breeding sites select internodes rather than stumps. The females of some species of mosquitoes have developed behaviours that allow them to detect this type of microhabitat by examining the stems of bamboo in search of small holes, which are used to enter and oviposit, as observed during this study. Other causes could be found in the fluid that is retained in the internodes; this is a product of the exudates of the bamboo wall and functions as an attractant to some females, thereby helping them to detect those sites that are suitable for laying eggs.

\section{Predators and associated species}

The number of predator taxa was similar in internodes and stumps, being all dipterans, except a single adult individual of the small beetle Liodessus sp., found on a stump. This beetle is a common inhabitant of permanent, semi-permanent and temporary aquatic environments (Von Ellenrieder and Fernández 2000), but is occasionally found in phytotelmata other than bamboo (Campos and Fernández 2011). The top predators in internodes and stumps were the larvae of Toxorhynchites, each individual using a container. Similar observations were made during a previous study in the Paranaense forest, located in the northwest of Misiones province (Campos 2013). The presence of a single larva of Toxorhynchites per container could be due to the cannibalism and killing 
behaviour that is typical of species of this genus. In the stumps and internodes where Toxorhynchites larvae were present, the abundance and diversity of prey was low. However, this predator was positively associated with Wyeomyia in internodes, and with Aedes terrens in stumps. In both cases there was marked seasonality, the association with Wyeomyia occurring throughout the year, except spring, despite the fact that the predators as well as the prey were present in the internodes. In the stumps, the association between Toxorhynchites and Aedes terrens occurred only in spring, because during the other seasons, the species were not present together. Furthermore, the association with Toxorhynchites and Culicoides spp. (the most abundant species in the community) and Psychodidae, was negative and significant, allowing us to infer that the females of both taxa could be choosing for oviposition those containers where the predator is absent. Among the smaller predators, the Culicoides larvae can be highlighted for their abundance and although trophic generalists, they exhibit behaviours of predation (Aussel and Linley 1994). As Culicoides debilipalpis Lutz, an inhabitant of tree holes (Ronderos et al. 2010), the incidence of predation in bamboo by Culicoides spp. could be circumscribed by the presence of microorganisms because of their small size. Whereas Corethrella sp., a strict predator, being barely larger than Culicoides spp., has been observed preying on early stages of mosquitoes.

\section{Hypothetic trophic webs (Figures 3 and 4)}

The trophic webs established in the bamboos phytotelmata are subject to the size of the hole through which the organic matter and organisms will enter. In stumps, because the hole diameter is equal to the internal diameter of the bamboo stem, it would not be a limiting factor for the larger species. However, the internodes, the holes of which are lateral and small, somewhat limit the particle size of organic matter and also the size of the individuals that may enter. In stumps and internodes, the initial organic matter is allochthonous. In stumps, dissolved organic matter (DOM) comes from rainwater that runs off the foliage, whereas coarse particulate organic matter (CPOM) and fine particulate organic matter (FPOM) can enter as falling foliage passively or actively transported by arboreal arthropods that use the hollow stems as a refuge. In the internodes, the initial DOM comes from the rainwater run off from the stem, it remains low because of the small size of the hole in the wall. In the case of CPOM and FPOM they come mainly from transport by arboreal arthropods and by insects that drill the wall of the stem and from stem flow water. Once the community is settled, different species contribute organic matter through their faeces, exuviae and corpses. The lower level of the food chain would consist of microorganisms such as bacteria, protozoa and rotifers. The protozoa can be directly food for the larvae of Diptera, or indirectly modify the physical and chemical characteristics of the aquatic habitat, favouring the colonization of some species of insects tolerant to these conditions (Kurihara 1983). Larger detritivorous insects, such as syrphids, would feed on CPOM and FPOM, whereas smaller insects, such as mosquitoes and psychodids (filter feeders, grazers), feed on FPOM and DOM. The higher trophic level is composed of predators. In stumps, the most common predators were Culicoides spp., Corethrella sp. and Toxorhynchites spp. Sabethes Robineau-Desvoidy species, a 


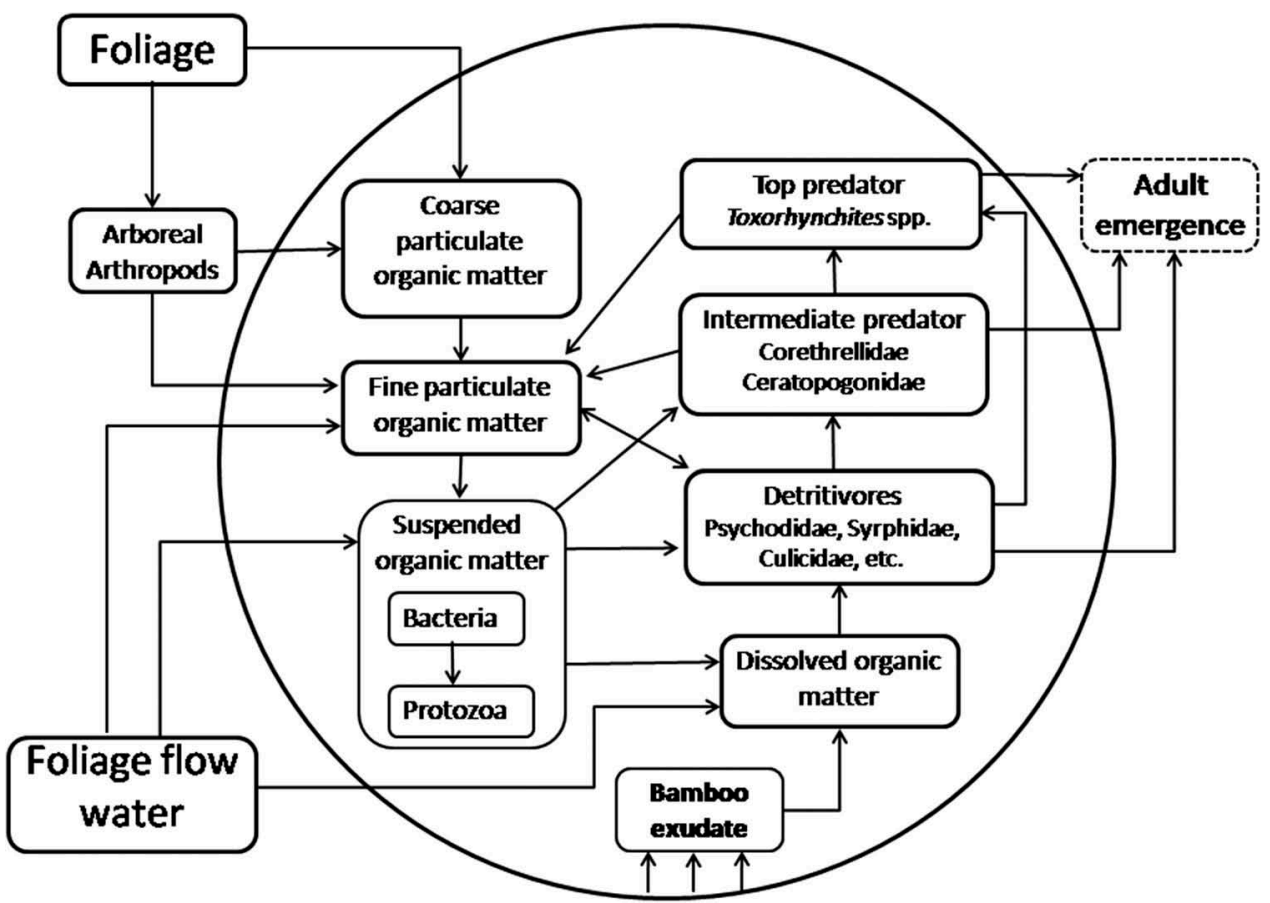

Figure 3. Hypothetic schema of a trophic web for stumps of bamboo community in Corrientes Province, Argentina. The circle represents the schematic stem wall, the arrows indicate energy flow.

facultative predator, which also ingests FPOM and DOM was present in the internodes and stumps. Intermediate predators were Culicoides spp. and Corethrella sp., preying on microorganisms and early stages of detritivores, respectively. In both communities, as already mentioned, Toxorhynchites larvae were the top predators. In our bamboos, unlike those of Louton et al. (1996) describing the internodes of Guadua weberbaueri, in Peru, the food chain does not include nymphs of dragonflies, snakes and tree frogs. The aquatic community to be established in the internodes will depend in part on the insect that produces the opening and the thickness of the bamboo wall. Louton et al. (1996) described a hypothetical food chain for Guadua weberbaueri, starting from internodes drilled by an orthopteran (katydid) that produces narrow slits separated by thin bridges with the ovipositor, which after a while will give rise to larger holes as a result of the rupture of the bridges because the wall of a bamboo stalk is thin. Hence, there are large holes allowing the entry of larger organisms, such as small vertebrates. In contrast, Campos (2013) noted that the holes of the bamboos Guadua trinii and Guadua chacoensis, whose walls are thick (about 2-3 cm) and hard, are of small diameter (about $5 \mathrm{~mm}$ ), which limits the entry of vertebrates and large arthropods. Furthermore, regardless of hole size, a decrease in the number of species becomes extreme in the southernmost area of the forest. In recent investigations (unpublished data) conducted in Guadua trinii internodes in Selva Marginal Punta Lara $\left(34^{\circ} 51^{\prime} \mathrm{S}, 57^{\circ} 52^{\prime} \mathrm{W}\right)$, Buenos Aires, no mosquitoes were found. 


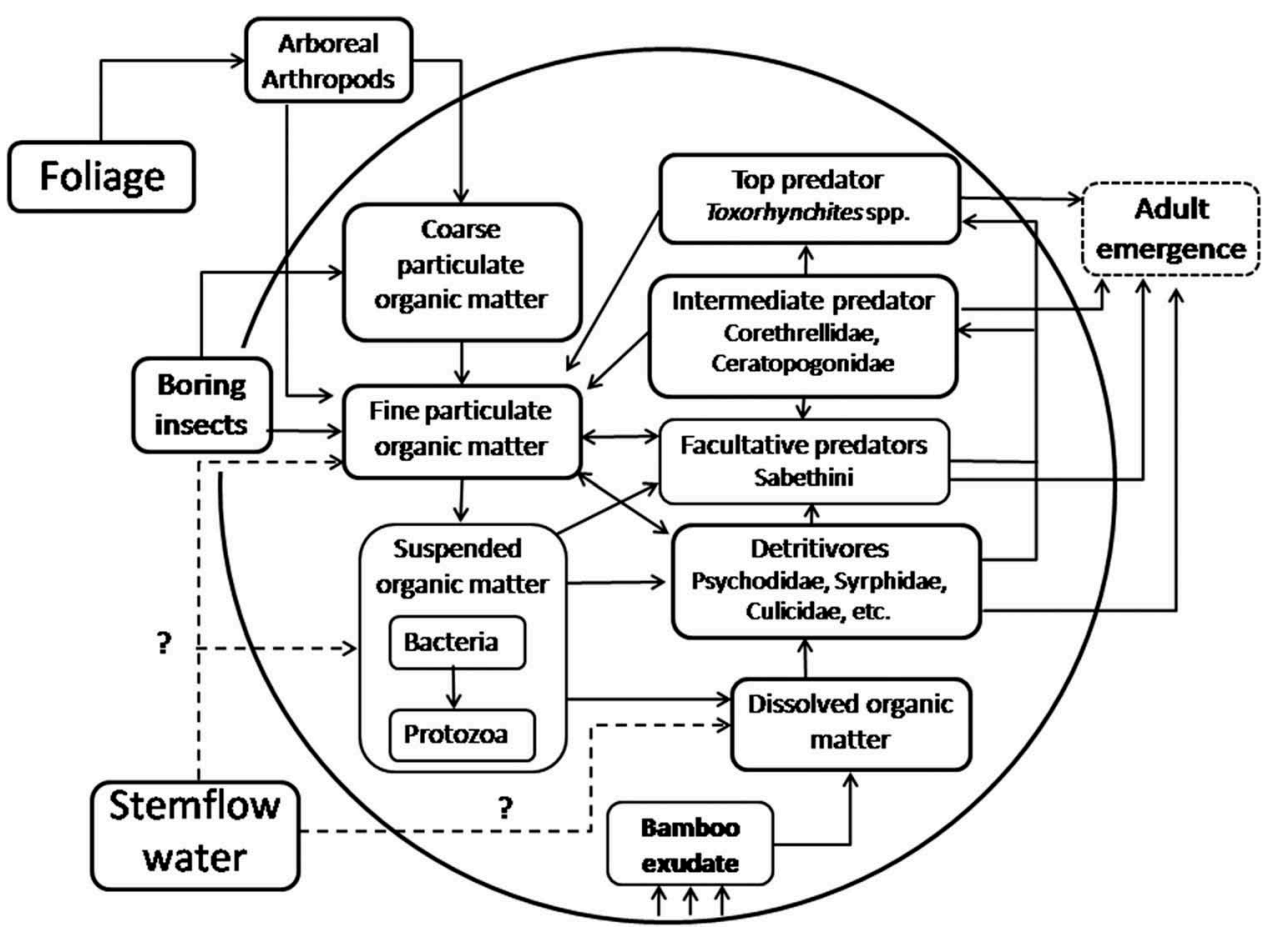

Figure 4. Hypothetic schema of a trophic web for internodes of bamboo community in Corrientes Province, Argentina. The circle represents the schematic stem wall, the arrows indicate energy flow. Dashed arrows indicate that input of stem flow water could be not relevant.

\section{Conclusions}

This study shows that the variation in the morphology of the container formed by bamboos, provides different microhabitats, leading to segregation of species by type of container, and allowing each of them to establish aquatic communities with differences in diversity. On the other hand, it suggests that the stumps are an important microhabitat that could be facilitating the spreading of macroinvertebrates that are often found living in tree holes. Regarding food webs established in stumps and internodes, differences in the composition of the species that play equivalent roles in each of the studied phytotelmata can be found.

\section{Acknowledgements}

I wish to thank Martín Kowalewski, Director of the Estación Biológica de Corrientes (EBCO) for logistic help and the provision of a licence to collect. I wish to thank Florentina Díaz, Pablo Marino and Marcela Ronderos (Facultad de Ciencias Naturales y Museo, Universidad Nacional de La Plata) for taxonomic determination of Ceratopogonidae, and Mónica Caviglia (ILPLA) for improvement of the English text. I also thank Arnaldo Maciá for his comments and suggestions on the preliminary manuscript and anonymous reviewers for their suggestions. The author is a member of the Research Career of CONICET. This is a contribution of the Instituto de Limnología: Journal Serie No. 936. This work was supported by Consejo Nacional de Investigaciones Científicas y Técnicas [PIP 0381]. 


\section{Disclosure statement}

No potential conflict of interest was reported by the author.

\section{References}

Aditya G, Tamang R, Sharma D, Subba F, Saha GK. 2008. Bamboo stumps as mosquito larval habitats in Darjeeling Himalayas, India: a spatial scale analysis. Insect Sci. 15:245-249.

Aussel J-P, Linley JR. 1994. Natural food and feeding behavior of Culicoides furens larvae (Diptera: Ceratopogonidae). J Med Entomol. 31:99-104.

Barajas JG, Suaza VJD, Torres GC, Rśa GL, Uribe-Soto S, Porter CH. 2013. Mosquitoes (Diptera: Culicidae) associated to Guadua in municipalities of Anserma, Hispania and Jardin, Colombia. Rev Colomb Entomol. 39:132-140.

Borkent A. 2008. The frog-biting midges of the world (Corethrellidae: Diptera). Zootaxa. 1804: $1-456$.

Cabrera AL, Willink A. 1980. Biogeografía de América Latina [Biogeography of Latin America]. Serie de Biología, Monografía 13. Washington (DC): Organization of American States.

Campos RE. 2013. The aquatic communities inhabiting internodes of two sympatric bamboos in Argentinean subtropical forest. J Insect Sci. 13:1-17. Available from http://www.insectscience. org $/ 13.93$

Campos RE, Fernández LA. 2011. Coleopterans associated with plants that form phytotelmata in subtropical and temperate Argentina, South America. J Insect Sci. 11:1-18.

Campos RE, Lounibos LP. 1999. Eryngium spp. (Umbelliferae) as phytotelmata and their Culex (Culex) inhabitants in temperate Argentina. J Am Mosq Control Assoc. 15:493-499.

Campos RE, Spinelli G, Mogi M. 2011. Culicidae and Ceratopogonidae (Diptera: Nematocera) inhabiting phytotelmata in Iguazú National Park, Misiones province, subtropical Argentina. Rev Soc Entomol Arg. 70:111-118.

Darsie Jr. RF. 1985. Mosquitoes of Argentina. Part I. Keys for identification of adult females and fourth stage larvae in English and Spanish (Diptera, Culicidae). Mosq Syst. 17:153-253.

Davis ED. 1944. Larval habitats of some Brazilian mosquitoes. Rev Entoml. 15:221-235.

Fish D. 1983. Phytotelmata: flora and fauna. In: Frank JH, Lounibos LP, editors. Phytotelmata: terrestrial plants as hosts of aquatic insect communities. Medford (NJ): Plexus; p. 1-27.

Hurlbert SH. 1969. A coefficient of interspecific association. Ecology. 50:1-9.

Kovac D, Azarae I. 1994. Depredations of a bamboo shoot weevil: an investigation. Nat Malaysia. 19:115-122.

Kovac DJ, Streit B. 1996. The arthropod community of bamboo internodes in Peninsular Malaysia: microzonation and trophic structure. In: Edwards DS, Booth WE, Choy SC, editors. Tropical rainforest research. Monographiae Biologicae 74. Dordrecht: Kluwer Academic Publishers; $p$. 85-99.

Kurihara Y. 1983. The succession of aquatic dipterous larvae inhabiting bamboo phytotelmata. In: Frank JH, Lounibos LP, editors. Phytotelmata: terrestrial plants as hosts for aquatic insect communities. Medford (NJ): Plexus; p. 55-76.

Lane J. 1953. Neotropical Culicidae. Vol. 1. São Paulo (Brazil): University of São Paulo.

Londoño X. 1996. Diversity and distribution of new world bamboos, with special emphasis on the bambuseae. INBR. 8:1-16.

Lounibos LP, Frank JH, Machado-Allison CE, Navarro JC, Ocanto P. 1987. Seasonality, abundance and invertebrate associates of Leptagrion siqueirai Santos in Aechmea bromeliads in Venezuelan rain forest (Zygoptera: Coenagrionidae). Odonatologica. 16:193-199.

Louton J, Gelhaus J, Bouchard R. 1996. The aquatic macrofauna of water-filled bamboo (Poaceae: Bambusoideae: Guadua) internodes in a Peruvian lowland tropical forest. Biotropica. 28:228-242.

Lozovei AL. 1998. Mosquitos dendrícolas (Diptera, Culicidae) em internódios de taquara da floresta Atlântica, Serra do Mar e do Primeiro Planalto, Paraná, Brasil. [Dendrícolas mosquitoes (Diptera, 
Culicidae) in bamboo internodes of the Atlantic forest, Serra do Mar and Primeiro Planalto, Paraná, Brazil]. Braz Arch Biol Tech. 41:501-508.

Lozovei AL. 2001. Microhabitats de mosquitos (Diptera, Culicidae) em internódios de taquara na mata atlântica, Paraná, Brasil [Microhabitats of mosquitoes (Diptera, Culicidae) in internodes of bamboo in the rainforest, Paraná, Brazil]. Iheringia Sér Zool. 90:3-13.

Macdonald WW. 1962. Observations on the biology of Anisodera goryi Baly in Malaya (Coleoptera: Chrysomelidae). Pac Insects. 4:413-416.

Magurran AE. 1988. Ecological diversity and its measurement. London: Croom-Helm.

Marti GA, Micieli MV, Maciá A, Lounibos LP, García JJ. 2007. Seasonality and abundance of the mosquito Isostomyia paranensis from phytotelmata in temperate Argentina. J Am Mosq Control Assoc. 23:252-258.

Martins Da Silva A, Nunes V, Lopes J. 2004. Culicids associated with bamboo internodes and bromeliads, with emphasis on Aedes (Stegomyia) albopictus (Diptera, Culicidae) in the Atlantic Forest, Paraná, Brazil. Iheringia, Sér Zool. 94:63-66.

Mogi M, Suzuki H. 1983. The biotic community in the water-filled internode of bamboos in Nagasaki, Japan, with special reference to mosquito ecology. Jap J Ecol. 33:271-279.

Montero G, Feruglio C, Barberis IM. 2010. The phytotelmata and foliage macrofauna assemblages of a bromeliad species in different habitats and seasons. Insect Conserv Diver. 3:92-102.

Muzón J, Muñoz SW, Campos RE. 2010. The larva of Mecistogaster amalia (Odonata: Pseudostigmatidae). Int J Odonatol. 13:137-144.

Nugues MM, Bak RPM. 2006. Differential competitive abilities between Caribbean coral species and a brown alga: a year of experiments and a long-term perspective. Mar Ecol Prog Ser. 315:75-86.

Ronderos MM, Cazorla CG, Spinelli GR. 2010. The immature stages of the biting midge Culicoides debilipalpis Lutz (Diptera: Ceratopogonidae). Zootaxa. 2716:42-52.

Scheirer C, Ray W, Hare N. 1976. The analysis of ranked data derived from completely randomized factorial designs. Biometrics. 32:429-434.

Sokal RR, Rohlf FJ. 1995. Biometry. New York: W. H. Freeman.

Sota T, Mogi M. 1996. Species richness and altitudinal variation in the aquatic metazoan community in bamboo phytotelmata from North Sulawesi. Res Popul Ecol. 38:275-281.

Stehr FW, editor. 1987. Immature insects. Vol. 1. Dubuque (IA): Kendall and Hunt.

Stehr FW, editor. 1991. Immature insects. Vol. 2. Dubuque (IA): Kendall and Hunt.

Sunahara T, Mogi M. 1997. Distributions of larval mosquitoes among bamboo-stump pools which vary in persistence and resource input. Res Popul Ecol. 39:173-179.

Sunahara T, Mogi M, Selomo M. 1999. Mosquito immatures in drought-prone and droughtresistant bamboo stumps in Flores, Indonesia. J Am Mosq Control Assoc. 15:271-275.

Von Ellenrieder N, Fernández LA. 2000. Aquatic Coleoptera in the Subtropical-Pampasic ecotone (Argentina, Buenos Aires): species composition and temporal changes. Coleopt Bull. 54:23-35.

Wolda H. 1981. Similarity indices, sample size and diversity. Oecologia. 50:296-302.

Zequi JAC, Lopes J. 2001. Culicideofauna (Diptera) encontrada em entrenós de taquara de uma mata residual na įrea urbana de Londrina, Paraná, Brasil. Revta Bras Zool. 18:429-438. 